\title{
Editorial: About the Relevance of Snow Microstructure Study in Cryospheric Sciences
}

\author{
Maurine Montagnat ${ }^{1,2 *}$, Guillaume Chambon ${ }^{3}$, Johan Gaume ${ }^{4,5}$, Pascal Hagenmuller ${ }^{2}$ and \\ Melody Sandells ${ }^{6}$ \\ ${ }^{1}$ Univ. Grenoble Alpes, CNRS, IGE, Grenoble, France, ${ }^{2}$ Université Grenoble Alpes, Université de Toulouse, Météo-France, CNRS, \\ CNRM, Centre d'Études de la Neige, Grenoble, France, '3 Université Grenoble Alpes, INRAE, UR ETNA, St-Martin-d'Hères, \\ France, ${ }^{4}$ Ecole Polytechnique Fédérale de Lausanne (EPFL), Lausanne, Switzerland, ${ }^{5}$ WSL Institute for Snow and Avalanche \\ Research SLF, Davos Dorf, Switzerland, ${ }^{6}$ Northumbria University, Newcastle upon Tyne, United Kingdom
}

Keywords: snow, microstructure, mechanical properties, optical properties, microCT

\section{Editorial on the Research Topic}

\section{About the Relevance of Snow Microstructure Study in Cryospheric Sciences}

Snow is an ubiquitous material in the Earth cryosphere and knowledge of its physical, electromagnetical and mechanical properties is critical for many applications such as estimating the Earth energy balance in a changing climate, forecasting avalanches or predicting water run-off.

Snow on Earth exists close to its melting point and presents a high porosity. Active metamorphism leads to the existence of a wide range of snow forms, usually described under the term "microstructure". This Research Topic emphasizes the link between snow microstructure and snow properties but also illustrates that the exact definition of snow microstructure highly depends on the considered application, scale, and the available instruments in the field or in the coldroom. Microstructural proxies range from a complete description of the $3 \mathrm{D}$ arrangement of ice and pore space obtained by X-ray microtomography (microCT), to density measurements recovered by remote sensing techniques.

Historically, snow microstructure was classified visually by grain size and shape with a crystal card and magnifying glass (Fierz et al., 2009). Langlois et al. revisit this classical technique by means of micro-photographs taken under angular directional LED lighting. Numerical processing of the micro-photographs enables the automatic retrieval of the size distribution and specific surface area of thousands of snow grains. Moreover, different light angles help reduce the bias caused by a 2D representation of 3D grains. The directional LED technique appears as a cheap, efficient and field adapted tool to characterise snow microstructure and give input for Radiative Transfer Models. The main limitation remains the necessity to individualise grains in the material, which questions (again) the definition of a snow grain.

Microstructural properties govern mechanical properties of snow. Conversely, the mechanical response of the material can be analyzed as a proxy of the microstructure. Cone penetration tests as the Snow Micro Penetrometer (Schneebeli and Johnson, 1998), are well adapted to take up the challenge of providing microstructural proxies from simple mechanical field tests. However, a rigorous inversion of the penetration signals requires a detailed investigation of the interaction between the cone tip and snow microstructure. Peinke et al. combine cone penetration tests laboratory experiments and in-situ microCT characterisation to quantify $3 \mathrm{D}$ grain displacements in the sample. They observe both compaction and local dilation around the cone tip, and evaluate the extent of the compaction zone. Comparisons with currently existing models point out their limitations. 
The mechanical response of snow is often modeled based on microCT measurements by Discrete Element approaches that consider snow grains as (e.g., spherical) individual elements interacting through contact forces (Hagenmuller et al., 2015). Willibald et al. tackle the problem of evaluating these micro-mechanical approaches using analogous snow samples with simplified geometry. They present mechanical experiments performed on synthetic samples made of sintered ice beads. They focus on the role of grain arrangement and sintering on the evolution of some mechanical properties (Young's modulus and compressive strength), and show that ice beads assembly response is consistent with near-natural snow.

To avoid manipulating extremely fragile snow samples, Lieblappen et al. show that ultrasonic waves can be used to retrieve snow porosity and tortuosity. They consider ultrasonic reflections instead of classical transmissions suitable for stronger samples (Umnova et al., 2005). Porosity is measured with only $8 \%$ difference with microCT measurements, while tortuosity shows larger discrepancies, depending on the snow type. This technique is sensitive enough to detect changes over a single day in fresh snow. With the technical aspects well detailed, transfer of the technique to field conditions appear highly feasible and opens new opportunities.

Understanding the process of snow to firn and ice densification is key for retrieving the accurate delta-age between ice and air trapped along ice cores, and thus the interpretation of climate records. Most densification models stand on 1D geometry and simplified mechanical schemes (Lundin et al., 2017). Fourteau et al. report here on an attempt to take a proper account of the real firn microstructure (obtained from microCT) together with a physically-based treatment of surface diffusion in the pores and viscoplastic deformation of the ice matrix. By doing so, based on the Level-Set formalism to track the ice/pore interface, they decipher the precise mechanisms at play during pore closure.

Montagnat et al. present the first continuous, high-resolution profiles of both snow microstructure (by microCT) and crystallographic fabric in Greenland surface snow. A clear seasonal signal from alternating temperature gradients is recovered from the anisotropy parameters. It is also shown that in the warmest conditions, load over the deepest snow layers might imprint the crystallographic fabric. Interestingly, Moser et al. analyze a $3 \mathrm{~m}$ Antarctic snow core and similarly find a

\section{REFERENCES}

Fierz, C., Armstrong, R. L., Durand, Y., Etchevers, P., Greene, E., McClung, D. M., et al. (2009). "The international classification for seasonal snow on the ground." in IHP technical documents in hydrology 83. Paris, France: UNESCO-International Hydrological Programme.

Hagenmuller, P., Chambon, G., and Naaim, M. (2015). Microstructure-based modeling of snow mechanics: a discrete element approach. Cryosphere 9 (5), 1969-1982. doi:10.5194/tc-9-1969-2015 seasonal pattern in snow anisotropy. On top of that, they combine isotope and trace element analysis with microCT to reconstruct the deposition history from the core. Both studies offer new insights in snow densification processes.

While a useful tool for dating, chemical composition of snow can also affect its mechanical and electromagnetic properties. Courville et al. complement the existing research on dust deposition impact on snow by focusing on the location of dust within the microstructure and its microbiological content. MicroCT observations locate dust particles mostly in the snow grains, at the snow/pore interface, leaving contact with the air and biological elements. Clues are given that dust could also interact with metamorphism processes. These data could help tracing the origin of dust and its evolution with time. Measurements of microbial communities suggest links between dust and microbial impact on snowpack characteristics.

Finally, Adachi et al. offer new perspectives on the characterisation of liquid water content in snow by using Magnetic Resonance Imaging (MRI). In contrast to classical calorimetry and dielectric measurements, MRI is nondestructive and gives access to distribution of water in the sample at a millimetric resolution. Besides providing a validation of the method, they illustrate its potential through measurements of the hysteresis of the snow-water retention curve during wetting-drying cycles.

The state-of-the-art review gathered in this Research Topic illustrates how available techniques for snow microstructure characterisation have come a long way since hand lens measurements. Advent of microCT constituted a step change to decipher the variety of geometrical arrangements in different snow types, and bridge the gap between microstructure and macroscopic properties. Future works will go further in complementing microCT measurements with MRI, crystallographic, chemical and biological analyses, in order to provide ever deeper insights into fundamental processes such as melt drainage, avalanche formation, dust origins, and formation of climatic records.

\section{AUTHOR CONTRIBUTIONS}

MM wrote the first draft of the Editorial based on the content of the articles from the Research Topic. The other authors all equally participated in correcting, modifying and improving the first version toward the final one.

Lundin, J. M. D., Stevens, C. M., Arthern, R., Buizert, C., Orsi, A., Ligtenberg, S. R. M., et al. (2017). Firn model intercomparison experiment (firnmice). J. Glaciol. 63, 401-422. doi:10.1017/jog.2016.114

Schneebeli, M., and Johnson, J. B. (1998). A constant-speed penetrometer for highresolution snow stratigraphy. Ann. Glaciol. 26, 107-111. doi:10.3189/ 1998AoG26-1-107-111

Umnova, O., Attenborough, K., Shin, H.-C., and Cummings, A. (2005). Deduction of tortuosity and porosity from acoustic reflection and transmission measurements on thick samples of rigid-porous materials. Appl. Acoust. 66, 607-624. doi:10.1016/j.apacoust.2004.02.005 
Conflict of Interest: The authors declare that the research was conducted in the absence of any commercial or financial relationships that could be construed as a potential conflict of interest.

Copyright (C) 2020 Montagnat, Chambon, Gaume, Hagenmuller and Sandells. This is an open-access article distributed under the terms of the Creative
Commons Attribution License (CC BY). The use, distribution or reproduction in other forums is permitted, provided the original author(s) and the copyright owner(s) are credited and that the original publication in this journal is cited, in accordance with accepted academic practice. No use, distribution or reproduction is permitted which does not comply with these terms. 